\title{
正視一聞科学——生物統計学和田間技术
}

\author{
备 維 廉
}

(云南大学)

\section{一 生物統㖕学与田間技术的畫义}

生物統計学是統計学的一个分枝。它是数学的理諭和方法在生物学中的綜合应用,

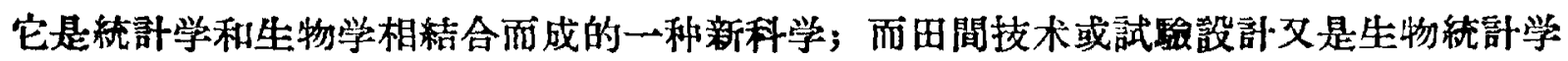
的理諭和方法在田間試駼上的应用与發展, 它是生物䊺計学在农学中新發展而成的一部 門。在生物学研究及农事試驗的設計規划和分析研究上，生物統計学和田間技术不仅帮 助生物学家和农学家对于試驗覌測所得盗料进行科学的分析研究, 得出正确的結論, 而 且可以帮助研究者对于所作覌測和試驗訂出正确的設計和規划，使試驗和观測的資料和 結果确能表示出現像的本買, 正确地求得現像的冥实情况和規律性。它对我倗正确地認 識生物界及生物和自然因素的关系, 以及在提傐生物学和农学的試驗研究的科学性方面, 都是有很大的作用的。作者謹本“百家孚鳴”的方針，提出生物統計学和田間技术的重要 性問題, 目的是想引起科学界重視这門有用的科学, 玤进而在生物学和农学部門里恢复 对它郡的講授、应用和研究。

\section{二 分析变因是生物较部学要要目的之一}

这里所要談的是如何实事求是地看待和处理生物界的遭傳与变异的問題, 并把它作 为生物統計学和田間技术的理論基础, 来正視生物統計学和田間技术的理論和应用的問 題。生物現像的特質，首先是生物有机体与其外界环境条件構成一个不可分制的統一体， 其次，生物体本身的遗傳性和变异性也是一个矛盾統一的問題。在外界条件相对不变的 情况下, 由于造傳性的保守性占优势, 則遗傳性即正常表現为䢙傳現像; 但当外界条件發 生显著改变的情况下，則生物体即可因适应生存而被迫發生改变，即产生变异現象，若 此变异是可以遗傳的, 則称之为遗傳的变异, 意即遗傳性永了改变。唯当外界条件的 改变不超出某物种及其品种的遺傳性的反应范葍, 虽不致引起該生物体遭傳性的改变, 但却显渚地影响到該生物体的遗傳性表現时, 也必引起生物体的变异; 这种变异虽然暫 时是不遗傳的, 但却可能是很显著的。这种变异不仅是有原因的, 而且原因还可能是多 种多样的。因为这种变异的原因常是可知的, 可以叫做定因变异。此外在生物体所处的 外界环境条件的整体中，除了一些已知的变因外，还有許多微小而晋遍存在的变因，假 定它們的存在是各自独立, 备具有不能同时發生的正負輕徽效能, 則由它倗共同組成 的無数微小而不同的众多小环境的次数分配是合于二愐式展开式的, 而且这些小环境差 
异在均一土地上的組成和分布都是逢机的, 正因为是逢机的, 所以由它們所影响于相对 一致的生物群集而生的各种程度的微小变异也是逢机的。这种变异称为逢机变异。因为 份無法由人力来控制它，故在生物統計学和田間技术上把它作为佔計机差的来源。

由上所遮，橫看生物界的每一物种及其品种甚至純系的后代中，均是有变异的，变 异可以是遺傳的或不遺傳的。在不遗傅的变异中开可分为定因变异及逢机变异。这些变 异是加在生物体遺傳性上的外衣, 是生物体頲傳性在具体条件下表現时必然任随的現像。 所以我㑚要研究物种及其品种的遗傅性或研究任何处理对于某物种及其品种的道侮性的 作用，均要先对各种变因加以分离和控制，才能求得眞正的遗侮效能或处理效能，比 各品种或处理的好坏，分析生物現象的实質和規律。粉看生物界的每一物种及桨品种的 這傳現像，均是有其遗傅性和变异性的。同样，要研究某生物种及其品种的選估性和变

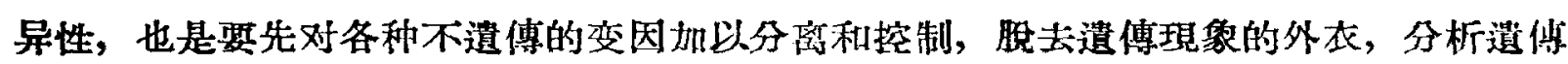
性的本質或求出变异性的規律。生物統㖕学和田間技术的主要任务，便是通过周密的試 羷設計或取样技术, 設法控制定因变异及减少逢机变异, 使試項(品利造傅性或处理效能) 差异逼镇表現，机差估值合理降低; 抹利用合理的統計分析，分別估計試項变量、定因

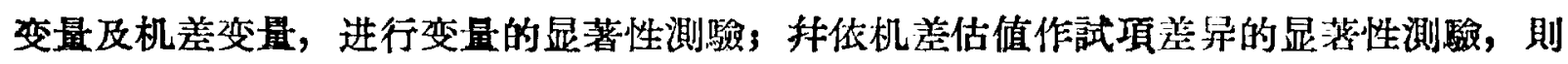
趾验的精确性既可提调，而試驗的結果自可正确的求出。

此外，若是我倚同时覌測某生物体群集的二种或二种以上的性狀时，便又可能㧺生 相关变异，即一种变因同时影响二种或二种以上的性狀，使这些性狀的遗賃性表現时發 生某种程度的相关現像。因为这些性狀的遺傳性表現对某种变因的反应, 可能是一致的, 也可能是相反的，所以相关变异的相互关系又有正相关或負相关之分. 不論相关变异的 相互关系之为正或負，而相关变异也同样是有定因变异和逢机变异雨大类的。文利用亲 代和子代間的相关現象，同样是可以研究某性狀的遣傳現象的。似此等相关变异的分析 究, 均可以利用生物統計学和田間技术的方法, 来估計㓂实的相关程度。

\section{三 在研究工作中如何应用生物統計学和田間技术的理論和方法}

在講授、应用或研究生物統計学和田間技术时, 不能偏重于統計数理, 而且也不能 机械地套用統計公式, 我佂必須將数学理論和統計方法与生物学和农学的理論和实际很 好的結合起来，方不致有削足适履、乱用公式或張冠戴、統計失直的錯誤。因为脱 实际的理䜽和不合理論的方法，同样是会导致失敗和錯棓的。

在研究任何生物現像或农学問題时, 首先是就样本材料或試驗材料进行精密的 覌 澌。取得覌測資料才能进行各种統計分析, 作出正确而科学的結論。所以，第一步工作 便是取样技术或試驗設計問題。有了合理的样本材料或試驗材料, 通过观測記录, 才能进 行各种的統計分析。正因为覌測材料的多少是与其代表性成正比例的, 所以覌測材料总 是相当多的，單取得此等众多的覌測值还是不能說明問題的眞的的，必須对覌測資料依 据材料来源进行合理的訜計分析, 方可使覌湘資料簡化明确, 求出現像或問題的本質。盗 料整理方法, 对于取样祆料可先进行分組列表种作变异圖示, 表示出現像的实質及其变 异情㫛, 进而估䚺統計常数, 如平均数、相关系数、变异系数等, 更科学地表示出現象 的点实情况、性狀的相关程度和变异的大小, 种利用各种常数的机美估值进行常数及其 
美异的显著性測驗, 作出科学的結論。对于有計划的試驗材料, 可針对原来的試驗設計 进行变是分析及亘变量分析, 依据机差变量进行变因变量的显著性测驗, 玤作試項美异的

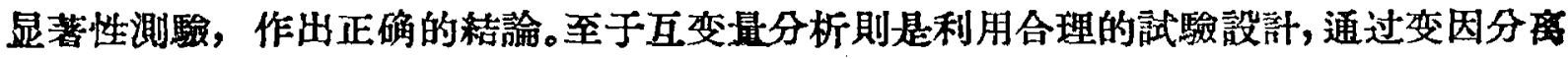
及統計分析, 求出各种变因所引起的相关系数, 抹作相关系数的显著性測驗, 即可求得 某二性狀在各种变因下的相关情形。此等統针方法的应用，对于生物学和依学的試駼研 究是十分重要的, 它不仅提供給研究工作者以整理材料和統計分析的科学方法, 而且提 供給研究工作者以思考問題和設計試驗的科学思想, 所以在我們的科学研觉工作中必須 很好的利用生物統計学和田間技术的理諭和方法。

关于試验設計和取样技术的理論和方法，也是十分重要的。首先在朵取样本时，必 先考察取样群集的純一性, 其次就是所取样本对于群集的代表性, 因样本是群集的代 表, 所以它必須能立分代表該群集, 这就率涉到取样技术和样本大小的間題; 假如群集 不絊或样本的代表性不够，不但会使絰計分析的結果不精确，甚而可能导致錯䜅的結喻。 至于試驗設計方面, 不但要槕选供試品种或决定供試处理, 确定試驗进行的地区和年限 以及供試品种数或处理租合数, 更重要的还是試区的大小和形狀, 品种或处理的排列, 区集的大小和形狀（区集的大小随品种或处理数的多少支試区的大小而定）及重处次数 的多少等，按照一定的設計方式作出合理的試驗設計及种植計划; 这情通过田間的硗培 管理及覌測記載，才能得出合理的統計資料。有了合理的試驗設計，才能达到分离变因

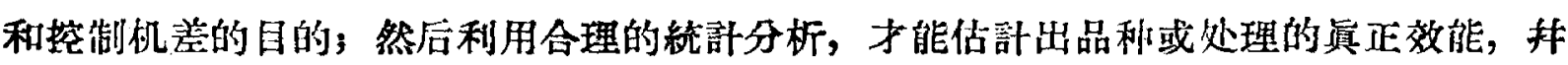
利用机前估値进行試項效能的美异显著性測定, 得出科学的結論。若是試駿的設計不合 理，必致机差不純，使試驗的精确性降低，或試項效能混杂，而無法比較，以致試驗的 粘果失真或錯誤, 若得出这种不正确的結論, 輕者常致試驗失敗, 重者可导致科学上或 生产上的損失。生物統棓学和田間技术的任务之一地就是研究这些問題, 所以我們必須 研究并应用它們。

\section{四 生物㓍計学和田間技术的毀展情况}

生物統計学的历史不过数十年, 而田間技术的成立才不过近二三十年的事, 但它們 在世界各国的墢展是迅速的，研究和应用是广泛的。研然最多而發展最快的是英国; 美 国則应用广泛而深入，但研究發展則較少，其他国家则应用虽多而研究則更少。到目前 为止，英、美而其他国家对生物統計学和田間技术的㩐授、应用和研究，均日篮广泛而 深入。它湖的应用范圈深入到生物科学的每一学科之中, 尤以农学、音牧学、遗傳学及 土堆肥料学为最多, 在促进生物学和农学各学科的發展料提高其科学性上, 是有很多貢 献的。

生物統計学和田間技术在我国的研究和应用, 虽不过二十多年的历史, 但其盛寀的 变迁确可分为雨个大的阶段。大钽在解放前是迅速發展的, 不仅在各大学农学院有生物

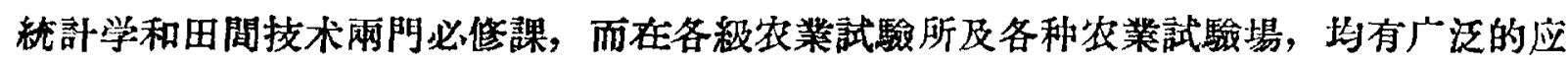
用。也正是因为它們在国內的發展太快了，在应用上多少产生些目目性，个別的或是試 驗設計及統計分析重过于覌測試驗对象的本身，或只筷求設計方法，而忽視試驗仿身的 精确性, 或只就覌測数字进行复杂的統計分析, 而不問覌測数字的叮靠性, 以致墢生試 
驗設計形式化或統計分析公式化的偏差, 这种应用上的偏差自然是应該約正的, 但利不能 因为这些个別現像就降低了生物統計学和田間技术的重要性和科学性。及至解放后由于 批判科学上的唯心主义和形而上学思想, 强調本森科院士所謂“科学是偶然性的敌人”一 語, 反对孟德尔、摩尔根等的遗傳学說, 以及强調米丘林遺傳学沒有应用生物統計学等, 發生了慙时的偏羑，影响所及，竟致方始發展的生物統計学及田閤技术，几乎由农学院 教学攻农学和生物学的試驗研究中被排除出去, 甚至連机差、机萃、逢机取样等統計术 語也無法再提了。这一趋势所引起的損失, 虽已漸为各方所發覚, 但还沟有看到有人提 出糾正的意見。希望科学界皮时重視这門重要的, 但被冾落了的科学, 恢复对它們的詳 授、应用和研究，这將对我国生物学和军学各科的發展起很大的作用。

\section{五 充分發揮生物続計学和田間技术的作用}

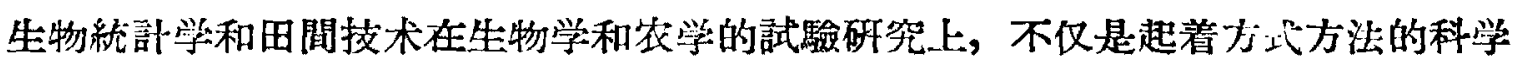
工具作用, 更重要的是还起着指导設計試驗和分析問題的作用, 所以它們在生物学和农 学的試驗研究及科学撥展上是有重要意义的。至于这門科学在应用上筜經發生某种程度 上的偏美，那是应該利正的，但不应因此就否認了这門科学的本身。拿李森科院士所謂 “科学是偶然性的敌人”一語来看, 如果理解为科学可以估計偶然性, 都么这句話就是正确 的, 而生物統訫学和田間技术的任务之一便是这样提出的, 共且通过試驗設計和紿計分 析也的确可以办到这一点。但是絕不可以否註机率的意义和否彗偶然性的存在, 更不能 借此来拒絶生物統計学和田問技术在生物学和农学上的应用。假使孟德尔的站豆試驗的 后代分离比的确是合于 $3: 1$ 或 $9: 3: 3: 1$ 等, 那么应用統計方法將紛乱的杂交后代的分离 材料, 整理为一定的比例关系, 找出遺傳性的規律，正是科学的起碼要求，也就是生物維 計学的应有的科学作用。此外在优生学中也最早地应用生物統計学的相关理諭来研究亲 子間的相关作用，以証实亲子間的遗傅現象，假使这种調查統計的結果的确能代表亲子

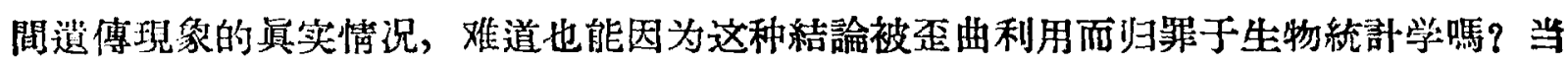
然不能这样浮浅的看問題。至于米丘林和貝尔班克沒有应用生物統計学也育成了很多优 良的品种, 那更不能作为反对生物紿訐学和田間技术在生物学和就学上应用的理由。問 題是我們如何更好地利用現有的科学知識、方法和工具, 来促进玤加强我們的科学研究 工作，提语我們的科学水本，抹尽快的把科学成就应用到生产建設上去。我們应該認倳 到生物統許学和田問技术在生物学和究学的試验研究中的应用, 不仅是合理的而且是必 需的; 因为它們不但可以帮助我們全面而深入地思考問題和分析問題，合理地設計試驗 或穼取样本; 而且可以帮助我們分析出生物現像或农事試驗当代的题实情况或对比关 系, 扑研究出它們在年度或世代間的垂淔关系。这样它們不但使我們把試驗研究計划放 在合理的可靠基础上，而且最后还把試驗研究的报告提高到科学水本上。因此我們必須 来研究抹發展这門有用的科学。 